\title{
Predicting high consumer-brand identification and high repurchase: necessary and sufficient conditions
}

\author{
Pedro Torres \\ CeBER and Faculty of Economics, University of Coimbra \\ Av. Dias da Silva, 165 \\ 3004-512 Coimbra - Portugal \\ Phone: +351 239 790584, Fax: +351 239790514 \\ E-mail: pedro.torres@uc.pt
}

\begin{abstract}
Mário Augusto
Institute of Systems and Robotics, CeBER and Faculty of Economics, University of Coimbra

Av. Dias da Silva, 165

3004-512 Coimbra - Portugal

Phone: +351239 790544, Fax: +351239790514

E-mail: maugusto@fe.uc.pt

\section{Pedro Godinho}

CeBER and Faculty of Economics, University of Coimbra

Av. Dias da Silva, 165

3004-512 Coimbra - Portugal

Phone: +351 239 790571, Fax: +351 239790514

E-mail: pgodinho@fe.uc.pt
\end{abstract}

Corresponding author: Pedro Torres

\section{Acknowledgements}

The authors gratefully acknowledge the useful comments and suggestions of three anonymous reviewers, which helped to significantly improve the article.

\section{Funding}

This research did not receive any specific grant from funding agencies in the public, commercial, or notfor-profit sectors.

(C) 2017. This manuscript version is made available under the CC-BY-NC-ND 4.0 license http://creativecommons.org/licenses/by-nc-nd/4.0/

This is a post-peer-review, pre-copyedit version of an article published in Expert Systems with Applications. The final version of the article is available online at: http://dx.doi.org/10.1016/j.jbusres.2017.05.029 


\begin{abstract}
The objective of this paper is to explore the necessary and sufficient conditions to obtain high consumer-brand identification (CBI) and high repurchase intentions (Rep). Different from most business research on $\mathrm{CBI}$ and Rep that is based on symmetric thinking, this paper uses asymmetric analytics and performs fuzzy set qualitative comparative analysis. The findings show that (1) although it is possible to identify the necessary conditions for very high consumer-brand identification and very high repurchase intentions, no combination of conditions is sufficient to achieve these outcomes; (2) affective drivers have more importance than cognitive drivers for obtaining high CBI; (3) the configuration solutions for high CBI include at least two antecedents; (4) high CBI is a sufficient but not necessary condition for high Rep; (5) high Rep can also be achieved if brand-self similarity and brand identity occur; and (6) memorable brand experiences alone may be enough to obtain high Rep.
\end{abstract}

Keywords: Consumer-brand identification; Repurchase intent; Memorable brand experiences; Brand identity; Brand social benefits; Brand-self similarity. 


\section{Introduction}

Despite the recent attention that has been devoted to consumer-brand identification (CBI) and the important insights that have been provided by the past research, it is also recognized that the knowledge of this phenomenon is still limited (e.g., Stokburger-Sauer, Ratneshwar, \& Sen, 2012; Elbedweihy, Jayawardhena, Elsharnouby, \& Elsharnouby, 2016). To advance the knowledge on CBI, this paper aims to identify the sufficient and necessary conditions that lead to high CBI and high repurchase intent (Rep), as well as the configurations that result in very high or low values of CBI and Rep. This configurational approach enables a better understanding of CBI and provides actionable insights, which leads to more efficient and effective marketing strategies.

CBI corresponds to “a consumer's psychological state of perceiving, feeling, and valuing his or her belongingness with a brand" (Lam et al., 2013, p. 235), and it is influenced by cognitive-based drivers and affective-based drivers. Cognitive-based drivers include brand-self similarity (BSS) and brand identity (BI), and affective-based drivers include brand social benefits (BSB) and memorable brand experiences (MBE). The relative importance of each of these categories is still controversial in the marketing literature. For example, Stokburger-Saur et al. (2012) suggest that affective drivers have a stronger role, while Bhattacharya and Sen (2003) indicate a major influence of cognitive drivers.

The previous research has suggested that the extent to which consumers identify with a brand influences Rep (e.g., Ahearne, Bhattacharya, \& Gruen, 2005) and brand loyalty (e.g., Bhattacharya \& Sen, 2003; Tuškej, Golob, \& Podnar, 2013; Yeh, Wang \& Yieh, 2016). Thus, in this paper, we also analyze the conditions that lead to Rep that also reflect brand loyalty. 
The present study is original and valuable both in theory and in methodology. The current research on CBI has been using symmetric methods, such as multiple regression analyses and structural equation modeling (e.g., Stokburger-Sauer et al., 2012; Lam et al., 2013; Wolter et al., 2016). These methods report the net effects of a set of independent variables on a dependent variable and focus on linear relationships (Woodside, 2013). In this paper, we resort to a different approach: we use fuzzy set Qualitative Comparative Analysis (fsQCA). This approach allows for the identification of the combinations of conditions that lead to a given outcome, and it also sheds light on the degree of sufficiency and the degree of necessity of those conditions. It takes into account the possible asymmetric effects of the variables, considering that, in some configurations, the presence of a given condition may contribute to reaching the outcome and, in other contexts, it may be its absence that leads to the outcome.

Conceptually, this research considers the cognitive-based and affective-based drivers of $\mathrm{CBI}$, and it investigates the combinations of cognitive-based and affective-based drivers that may lead to the outcomes of interest. The conceptual models are presented in Figure 1. First, the different configurations to achieve high CBI are assessed (step 1). Second, considering both high CBI and its antecedents, the solutions that lead to high Rep are analyzed (step 2). An analysis of the high, very high and low values of CBI and Rep is also performed.

\section{(Insert Figure 1 about here)}

The rest of this paper is organized as follows. In Section 2, the background on CBI and Rep is reviewed. In Section 3, the sample, data collection and measures are described, some aspects of the application of the method are introduced, and preliminary analyses are presented. 
The main analysis is based on a survey that was administered to a student sample with questions regarding a beer brand. The preliminary analysis includes contrarian case analysis, calibration, definition of consistency and frequency thresholds, and an analysis of necessary conditions. In Section 4, the results are presented, the predictive validity of the configurations is assessed and an analysis of the generalizability of the results is performed. To test the predictive validity, the sample was split into two random subsamples, and the models were estimated in a subsample and applied to the other. The models were also applied to a subset of older students and to a sample of airline customers to obtain some indications about their generalizability. In all of the analyses, the models show good performance in data sets that are different from the ones that were used to estimate them. The results are discussed in Section 5. Finally, in Section 6, the main conclusions are presented: the importance of affective drivers for CBI is acknowledged; in addition to the causal effect of CBI on Rep, the findings suggest that the presence of two cognitive drivers (BSS and BI) or of MBE could also lead to high Rep. The Appendices present the scale items and Cronbach's alpha coefficients and a robustness analysis to the calibration, consistency and frequency thresholds.

\section{Background}

Brands can be the facilitators of social identity creation and expression (Stokburger-Sauer et al., 2012), and consumers can identify with a brand that they perceive to match their self-concept (Wolter et al., 2016). Through this process, consumers satisfy their self-verification needs, which in turn enhances their attitudes and behavior toward the brand (Elbedweweihy et al., 2016). In fact, CBI is considered to be an antecedent of brand loyalty (e.g., Bhattacharya \& Sen, 2003; Tuškej, Golob, \& Podnar, 2013; Yeh, Wang \& Yieh, 2016), which contributes to positive brand equity (Torres, Augusto, \& Lisboa, 2015), creates competitive barriers (Yoo, Donthu, \& Lee, 
2000) and influences consumer preferences and purchase intentions (Cobb-Walgren, Ruble, \& Donthu, 1995).

Based on social identity theory, which includes cognitive, affective, and evaluative aspects, Lam et al. (2013) consider three key CBI antecedents: perceived quality (which is generally under the control of brand managers); self-brand congruity (which could be somehow managed by brand managers through positioning); and consumer innate innovativeness (which corresponds to an individual trait, beyond the control of brand managers). In fact, consumers look for a brand whose identity matches their own to fulfill consistency needs; however, they can also achieve the fulfillment of their self-esteem needs if the consumption of the brand helps them to form their ideal self-image (He, Li, \& Harris, 2012). Stokburger-Sauer et al. (2012) include the social benefits of a brand as an antecedent of CBI, and the construct is seen primarily as a cognitive representation with an abundance of emotional associations. Therefore, positive brand attitudes, which correspond to an individual's judgment of the goodness of brand (Park, MacInnis, Priester, Eisingerich, \& Iacobucci, 2010), are considered to be conceptually different than CBI.

Taking into account the key needs that are likely to drive identification in the marketing context, i.e., self-continuity, self-distinctiveness, and self-enhancement, Stokburger-Sauer et al. (2012) suggest that identification with a brand results from both cognitive and affective-based drivers. On the one hand, cognitive drivers result from the extent to which a person perceives a brand: $i$ ) to have a personality that is similar to their own, ii) to be unique or distinctive, and iii) to be prestigious. On the other hand, affective-based drivers include factors that are related to the consumption experience itself and address how CBI can be influenced by the extent to which consumers: $i$ ) feel that their interactions with a brand help them connect socially, i.e., result in 
social benefits, ii) perceive a brand to be warm, and iii) have memorable positive brand experiences. Stokburger-Sauer et al. (2012) noted that the influence of the affective antecedents of CBI could be stronger than the influence of cognitive antecedents.

\subsection{Drivers of CBI}

Lam et al.'s (2013) conceptual framework includes an instrumental driver (perceived quality) and a symbolic driver (self-brand congruity). Unlike the previous studies that have indicated a stronger influence of instrumental drivers on CBI (e.g., Kuenzel and Halliday, 2008), Lam et al. (2013) suggested that the symbolic drivers grow stronger over time, as opposed to the instrumental driver, which remains stable. Perceived quality could be useful in predicting the initial level of CBI; however, it may not sustain CBI over time. Therefore, the extent to which a consumer's personality overlaps with a brand's personality could have stronger effects on CBI.

Self-congruity refers to the matching process between the symbolic attributes of brands and the consumer's own self-image (Sirgy, 1985). The set of human characteristics that can be associated with a brand is usually described as brand personality, and the greater the overlap between a consumer's self-concept and brand personality, the more likely it is that the consumer to have a positive attitude towards the brand (Kuenzel \& Halliday, 2010). Moreover, consumers often purchase goods to express their identity (Aaker, 1997). The literature suggests that the relationship of self-brand congruity and consumer behavior is mediated by CBI (e.g., Bhattacharya \& Sen, 2003); however, some authors have found that self-congruity with a sponsorship event could influence brand loyalty (Sirgy, Lee, Johar, \& Tidwell, 2008). Brand-self similarity (BSS) plays an important role in the brand identification approach that leads to brand loyalty. 
Brand identity could be defined as the distinctive and relatively enduring characteristics of a brand (He et al., 2012; Bhattacharya \& Sen, 2003), and a brand tends to be more attractive when the identity is more prestigious and more distinctive (Stokburger-Sauer et al., 2012; He et al., 2012). In fact, brand prestige and brand distinctiveness are considered to be the two most salient brand identity characteristics (e.g., So, King, Hudson, \& Meng, 2017). However, Stokburger-Sauer et al. (2012) did not find evidence of a brand prestige predictive role, and recent studies have reported similar results (e.g., Wolter et al., 2016). In general, prestige indicates that an organization is well regarded by other people, whose opinions are valued, which means that it is respected, admired and well known (Bergami \& Bagozzi, 2000). If a brand's positioning is associated with a relatively higher status, this result could be regarded as brand prestige (Steenkamp, Batra, \& Alden, 2003), and the extent to which consumers perceive a brand image to be prestigious may influence their levels of self-esteem in identifying with the brand (Ahearne et al., 2005). Furthermore, consumption of prestige brands may improve consumers' social standing and self-expression (O'Cass \& Frost, 2002). Brand distinctiveness is often described as the perceived uniqueness of a brand's identity in relation to its competitors (e.g., Stokburger-Sauer et al., 2012). Marketing scholars have suggested that the degree of identification with a brand will be higher if consumers perceive the brand to be distinctive.

The use of brand prestige and brand distinctiveness as two different constructs implies that the former satisfies self-enhancement motives and the latter self-differentiation motives (Bhattacharya \& Sen, 2003). However, brand prestige results from a brand's unique know-how, specific attribute or overall quality, and the positive effect of brand prestige on purchase intention can be mediated by perceived quality, information costs saved, and perceived risk (Baek et al., 2010). Thus, it may be difficult to separate brand prestige from brand 
distinctiveness. The present study will focus on BI as a driver of CBI, keeping in mind that brand prestige and brand distinctiveness are two important characteristics of brand identity.

Regarding the more affective drivers of CBI, which consider consumers' interactions and encounters with a brand and other brand customers, this study follows the approach of So et al. (2017). Thus, the present research includes two theoretical constructs, BSB and MBE.

Stokburger-Sauer et al. (2012) defined BSB as the social interaction opportunities that are provided by a brand and suggested that consumers' perception that a brand provides brand social benefits will likely lead to CBI. Brands carry social and cultural meaning, and sometimes consumers form groups on the basis of a shared commitment to a brand (Thompson, Rindfleisch, \& Arsel, 2006). When positive attitudes toward a brand are generated, consumers tend to behave in such a way as to sustain those positive attitudes (Raghunathan, Naylor, \& Hoyer, 2006).

Brands that offer MBE are more likely to develop CBI (Stokburger-Sauer et al., 2012), and brands that promote consumer affection toward the brand tend to prompt greater purchase loyalty (Chaudhuri \& Holbrook, 2001). The self-referencing process that is promoted by some brands through the construction of brand-related stories and narratives produces affect-laden and easily retrievable memories, which tends to improve the strength of the connections between the consumer and the brand (Escalas, 2004). In fact, the perception of a brand is increasingly linked to a consumer's experience with the brand. Thus, a brand can create incremental value through brand experiences (Cliffe \& Motion, 2005). MBE could involve sensory perceptions, brand affect, and the participatory experiences that a consumer may seek with a brand (Schmitt, 2012). Certain brands could leave a strong affective charged mark on the consumer's consciousness, even if such brands are infrequently used (Stokburger-Sauer et al., 2012). 


\subsection{Analysis of CBI and Rep}

Given the trend of product commoditization that is enabled by the standardization of technology design and manufacturing processes, the capacity to create meaningful brand associations has become increasingly more important to differentiate a company's offering, in particular the associations that are related to consumers' self-identity (Chernev, Hamilton, \& Gal, 2011). The recent research on CBI has studied the antecedents and consequences of $\mathrm{CBI}$ using an additive and linear approach (e.g., Stokburger-Sauer et al., 2012). However, the phenomenon of CBI is complex, and, in spite of the acknowledged power of branding, customer loyalty is one of the most challenging issues that are faced by companies in a world of intense competition (Nyadzayo \& Khajehzadeh, 2016). In fact, with regard to brand loyalty, the previous marketing research makes a case for conjunctural causation: it is often noted that only a combination of conditions would lead to a desired outcome. For example, as reported by Chai, Malhotra, and Alpert (2015), most loyalty studies indicate that satisfaction alone is not sufficient to bond customers and, as noted by Nyadzayo and Khajehzadeth (2016), high service quality evaluation per se is insufficient to drive customer loyalty.

In the application that is made in this paper, we are not interested in the average effects of the antecedent variables on the outcome. Instead, we want to determine whether there are necessary conditions for high, very high, and low CBI and Rep intentions, and we want to know if alternative configurations of conditions are sufficient to achieve the same outcome. We do not assume that the effects of the antecedents are additive but instead that completely different combinations of those antecedents may lead to the same outcome. We must note that, in this application, it is of great interest to identify the sets of causal conditions that lead not only to high levels of the outcomes but also to very high levels and to low levels of the outcomes. 
Consumers with very high repurchase intentions are a subset of the set of consumers with high repurchase intentions whose answers show the most extreme (highest) scores concerning such intentions; that is, they have an extreme state of commitment to a brand.

An analysis of high, very high and low outcome values is also performed by Fiss (2011), in the context of company performance. In an asymmetrical analysis such as the one that is performed in this paper, the conditions that lead to very high outcome levels do not necessarily imply more extreme values of the variables that lead to high outcome levels. As is shown by Fiss (2011), very high outcome levels may be achieved by adding conditions to some of the configurations that are obtained for high levels, or by configurations that are based on different conditions. It is also possible that no configuration is sufficient to achieve such very high outcome levels.

\subsection{Tenets for predicting CBI and Rep}

Despite the relationships among the constructs that have already been tested in the previous research, the conceptual models and results are not consensual. The possible existence of different configurations that lead to the same outcome could be an answer to this ambiguity. Therefore, some tenets were proposed to guide the investigation, as follows.

First, it is to be expected that more than one antecedent of CBI will be present in the solutions for achieving high CBI. This is justifiable considering the drivers of CBI that have been established in the previous studies (e.g., So et al., 2017; Stokburger-Sauer et al., 2012) and building on the marketing literature that suggests that CBI is directly influenced by two categories of factors: $i$ ) one category that includes brand characteristics (such as prestige and distinctiveness) as is reflected in BI, and ii) another category that results in consumer-brand 
interactions, which includes social benefits and memorable brand experiences (So et al., 2017). Our goal here is also to better understand if the different configurations for high CBI include more cognitive drivers (BSS and BI) or more experiential (i.e., affect-rich) drivers (BSB and MBE), which is still controversial. Thus, we formulate the following tenet.

T1: The sufficient conditions for achieving CBI require the joint presence of more than one CBI antecedent (BSS, BI, BSB, and MBE).

Second, although the recent studies have proposed that CBI may result in higher brand loyalty (e.g., Kuenzel \& Halliday, 2010), the previous research has established a solid relationship between the antecedents of $\mathrm{CBI}$ and repurchase intentions. For example, brands can create value by providing memorable experiences (Cliffe \& Motion, 2005) and thereby enhancing greater purchase loyalty through the affection that they generate in consumers (Chaudhuri \& Holbrook, 2001). Moreover, some authors (e.g., Chernev et al., 2011) report the existence of limits to the benefits of positioning brands as a means of self-expression. Thus, high CBI could be sufficient, but not necessary, to obtain brand loyalty (hereby assessed through high repurchase intentions).

T2: High CBI is a sufficient, but not necessary, condition for high repurchase intentions.

In a world of intense competition, it is sensible to postulate that CBI per se will not be enough to achieve very high repurchase intention, which reflects an extreme state of commitment to a brand. Nevertheless, given the trend of product commoditization, brands increasingly compete for consumer identification, and the recent marketing research has well documented the importance of CBI (e.g., He et al., 2012). Thus, we formulate the following tenet.

T3: High CBI is a necessary, but not sufficient, condition for very high repurchase intentions. 
Finally, taking into consideration the asymmetry that is implicit in the proposed methodology (fsQCA), it can be expected that the conditions for low, high or very high outcome values will not be symmetrical.

T4: The conditions for low values of CBI and Rep are not the mirror opposites of the conditions for high or very high values of these outcomes.

\section{Methodology}

\subsection{Sample, data collection, and measures}

The present research focuses on Sagres brand, a market leader in the Portuguese beer market, which has a market share of approximately $45 \%$. The product category is widely available and well known, and it complies with the two most important criteria that should be observed when selecting a product (Buil, Chernatony, \& Martínez, 2013). The intense marketing activity of the

chosen brand and its market share ensure that the brand is well known among Portuguese consumers. Moreover, the positioning of beer brands is often based on a myriad of attributes that provide consumers with varied identity targets with which to identify (Wolter et al., 2016).

Because the likelihood of beer consumption is strongly linked to the 20-to-30 age segment of the market (e.g., Atilgan, Aksoy, \& Akinci, 2005, p. 241), and young people are the primary target of this beverage category (e.g., Zawrun, Metzer, \& Kunkel, 2006), a sample of university students is appropriate for this research. In addition, beer is the most commonly consumed alcoholic drink by university students (19-to-24 years), who are frequent consumers of this beverage (studies performed by SICAD, the Portuguese observatory of addictive behaviors). Moreover, the homogeneous nature of a student sample, with regard to both demographics and 
behavioral characteristics, which are non-theoretical variables, supports its use for theory application (e.g., Wyllie, Carlson, \& Rosenberger, 2014).

An online survey was conducted on undergraduate students who were registered in the academic year 2014/2015 at the University of Coimbra. The data were gathered between the $31^{\text {st }}$ of July and the $2^{\text {nd }}$ of September 2015, and 1,173 usable answers were obtained.

The study draws the scales from the literature with some adaptations. Consumer-brand identification and its antecedents were based on the measures that were proposed by StokburgerSauer et al. (2012) with some exceptions and refinements: i) the measure for brand-self similarity was based on Lam et al. (2013), which was an adaptation of Aaker's (1997) brand personality scale; ii) brand identity was based on the scales that were used for both brand prestige and brand distinctiveness by Stokburger-Sauer et al. (2012) because they are similar to the scale that has been used by other authors to measure brand identity (e.g., He el al., 2012); iii) the Stokburger-Sauer et al. (2012) scale for brand social benefits was used, but one item was added. For repurchase intent we adapted the scale that was developed by Kuenzel and Halliday (2008). The measurement instrument was pilot-tested, and the final version is presented on the Appendix I. The seven-point Likert scale that was used ranges from 1 ("strongly disagree" or "very little similarity") to 7 ("strongly agree" or "very similar"). All of the scales show high reliability (all of the Cronbach's Alpha coefficients are above 0.88).

Consumer-brand identification (CBI) and repurchase intent (Rep) are the outcomes of interest, and brand self-similarity (BSS), brand identity (BI), brand social benefits (BSB), memorable brand experiences (MBE) are the antecedents. However, CBI is both an outcome and an antecedent of Rep. 
The questionnaire also included information concerning sex, age, and the regularity of beer consumption by the respondents (Reg), although there is no indication that they would affect the outcomes. Still, those conditions were used to perform a necessary conditions analysis for both CBI and Rep, and they showed low consistency scores as necessary conditions. Thus, for the sake of parsimony, and to achieve interpretable configurations, they were removed from the configurational analysis. The score of each respondent in each construct was defined as the average of the answers to the different questions concerning the construct.

\subsection{Method and preliminary analysis}

\subsubsection{Modeling Causal Configurations}

Qualitative comparative analysis (QCA) involves the examination of the relationships between the outcome of interest and all of the possible combinations of binary states (i.e., presence or absence) of its predictors, by performing a systematic cross-case analysis that models the relationships among variables in terms of a set membership using Boolean algebra to identify configurations that reflect the necessary and sufficient conditions for an outcome of interest (Ordanini, Parasuraman, \& Rubera, 2014). Set-theoretic methods such as fuzzy set QCA do not use the conventional variable-based approach but rather treat configurations as different types of cases, and it is the combinations of attributes that give cases their uniqueness (Fiss, 2011). Recently, it has been increasingly advocated that researchers should craft and test theory using algorithms and move beyond conventional techniques such as multiple regression analysis (e.g., Woodside, 2013), and the use of complexity theory applications and fuzzy set qualitative comparative analysis (fsQCA) is growing in the sub-disciplines of management (Woodside, 2014). The main reason for this call relies on the fact that other techniques, such as multiple 
regression analysis, focus on net effects, which may be misleading: in Subsection 3.2.2 we explain that, in the data that are analyzed in this article, even when a clear main effect is found, there may be a substantial number of cases that contradict this main effect.

This does not mean that we advocate the complete replacement of regression analysis by configurational analysis. Regression analysis can provide some information about the relationship among variables that configurational analysis cannot. Following the reasoning of Vis (2012), quantitative approaches, such as regression, follow an "effects-of-causes" approach and attempt to estimate the average effect of the antecedent variables on the outcome. This approach works well if the effects are symmetrical and if both types of relationships among the variables and the outcome and the types of interactions between the variables are known. However, when the effects of the variables are asymmetrical, and the form of interactions among them is unknown, regression analysis may be inappropriate. In such situations, fsQCA may be able to provide useful information by identifying the combinations of conditions that lead to a given outcome. In a way, to use an expression of Vis (2012), fsQCA and regression analysis may provide "complementary lights" on a given topic. Therefore, as suggested by Schneider and Eggert (2014, p. 323), the choice of method should be based on the research question and on the theoretical links that are suspected in the data, i.e., causes-of-effects rather than effects-of-causes and complex and configurational rather than additive and linear. Although there are some approaches that may overcome the liabilities of regression in analyzing configurations, they also face significant shortcomings (Rihoux \& Marx, 2013, p.192).

Distinguishing between the degree of sufficiency of a condition and the degree of necessity of a condition, and determining the various paths that lead to a desired outcome can result in important actionable insights for practice. Such insights can help managers to focus 
marketing efforts, thereby improving the effectiveness and efficiency of their campaigns, and they can better justify their marketing actions (if the mechanisms are nonlinear, the fsQCA approach may produce a more realistic model; for example, the causes of low Rep are not necessarily the reverse of those that lead to high or very high Rep).

Thus, following the arguments that were presented by Schneider, Schulze-Bentrop, and Paunescu (2010), fsQCA is the appropriate method for this analysis because: i) asymmetrical causality is allowed, ii) combinations of various causal conditions, rather than a single condition, are considered to be linked to the outcome, iii) multiple causal paths that lead to the same outcome could be detected, thereby capturing the idea of equifinality (Fiss, 2007), and iv) links between the various combinations of causal conditions and the outcome are expressed as necessary and sufficient conditions. Additionally, it is possible to differentiate between causally core and causally peripheral conditions (e.g., Fiss, 2011).

In this application of fsQCA we address a large number of cases -in the literature this is often called a "large-N" application. QCA methods were originally used for small numbers of cases, for which researchers had deep knowledge of individual cases; however, they have been progressively extended to large numbers of cases (see, for example, Ragin \& Fiss, 2008; Woodside, 2012; or the examples mentioned by Rihoux 2006, p. 698). Rihoux (2006, p. 685) argues that fuzzy sets, in the context of QCA “... are actually quite well suited to large-N situations, i.e., to research designs in which the comprehension of each individual case matters much less." Large-N applications involve some adjustments in the way in which QCA methods are applied and in the analysis and interpretation of the results. Greckhamer, Misangyi, and Fiss (2013) compare the use of QCA methods with a large number of cases with their use with a small number of cases, and they find that, with a large number of cases, QCA methods can be 
used for inductive or deductive reasoning and for theory building and testing, larger frequency thresholds should be used (see Subsection 3.2.4), and the results of necessity and sufficiency analysis can be interpreted as patterns across many cases without returning to the original cases, which is of particular interest in the application that is presented in this paper. Emmenegger, Schraff, and Walter (2014) stress the importance of performing robustness tests in large-N applications to remedy the shortcomings that are associated with the weaker knowledge of individual cases, and we perform such robustness analysis in Appendix II. For a deeper discussion of the adjustments that should be made in large-N situations, we refer the reader to Emmenegger et al. (2014), Greckhamer et al. (2013) and Vis (2012).

To understand the causal configurations that lead to high consumer-brand identification and high repurchase intention (outcomes), the analysis of necessary and sufficient conditions was performed using fsQCA. The preliminary analysis includes contrarian case analysis and analysis of necessary conditions. In the next subsections, we also explain our calibration strategy and the definition of the thresholds that necessary for the application of fsQCA.

\subsubsection{Contrarian case analysis}

Even when there are significant main effects between constructs, there may also be an important number of cases that contradict such main effects. We tried to ascertain if this would be the case in the data that we are using by employing quintile cross-tabulations analysis (similarly to Woodside, 2016). All of the different combinations among the antecedents (A) and outcomes (O) were considered, and both the percentage of the cases that support the relationship $A \rightarrow O$ and the percentage of the cases that contradict it (either by indicating $\sim \mathrm{A} \rightarrow \mathrm{O}$ or $\mathrm{A} \rightarrow \sim \mathrm{O}$ ) were calculated. Although in all of the cases, the phi (degree of association between two variables) indicates a 
clear main effect relationship (phi values range from 0.558 to 0.838 ), it is also clear that many contrarian cases occur: the percentages of contrarian cases range from $6.5 \%$ (for the $\mathrm{MBE} \rightarrow \mathrm{CBI}$ relationship) to $16.1 \%$ (for the $\mathrm{BSB} \rightarrow \mathrm{Rep}$ relationship). This shows that the main effects may not tell the whole story, thus a configurational analysis may provide important insights on the data.

\subsubsection{Calibration}

To apply fsQCA, we must transform the original values of the variables into fuzzy scores (which are defined in the $[0,1]$ interval but should not be confused with probabilities). When the range of values of the variables is continuous or the number of possible values is large, the direct method of calibration is usually used (see Ragin, 2008, chapter 5) - this method maps the original values into fuzzy scores that belong to the $[0,1]$ interval. This method requires the specification of full membership and full non-membership thresholds and a crossover point of maximum ambiguity (Ragin, 2008). Each of these thresholds translates into a specific fuzzy value - it is standard to use fuzzy values of $0.95,0.05$ and 0.50 for the full membership and non-membership thresholds and for the crossover point, respectively (see, e.g., Ragin, 2008, chapter 5). Ideally, these thresholds should be defined in accordance with external standards; however, it is often impossible to find such standards. In their absence, many researchers use given percentiles of the distribution of the original values of the variables to define the thresholds. The $90^{\text {th }}, 10^{\text {th }}$ and $50^{\text {th }}$ percentiles of the values of the original distribution are commonly used to define the full membership and non-membership thresholds and the crossover point, respectively (e.g., Ho, Plewa, \& Lu, 2016, Navarro, Llinares \& Garzon, 2016, Ryan \& Berbegal-Mirabent, 2016). For the constructs BSS, BSB, BI and MBE, and for high consumer-brand identification (HCBI) and 
high repurchase intentions (HRep), we used this exact method with these percentiles. In fact, this approach - calculating the value of each variable by averaging their components, defined in Likert scales, and then using the direct calibration method based on the distribution percentiles is similar to the approach that is used by Ali, Kan, and Sarstedt (2016).

We acknowledge that there would be other possible ways to calibrate these constructs, which are fundamental in our analysis. This issue is particularly important because we do not have external standards to use as thresholds. To determine how sensitive the results are to the calibration decisions, and following the recommendation of Emmenegger et al. (2014), we performed a robustness analysis, which we present in Appendix II. This analysis shows that our results are quite robust to the use of different thresholds.

We also analyze different levels of the outcomes of interest, specifically, low and very high levels. Thus, we defined fuzzy variables regarding very high repurchase intentions and very high consumer-brand identification (VHRep and VHCBI, respectively) as well as regarding low values for these outcomes (LoRep and LoCBI, respectively). The calibration of the very high outcome levels is based on Fiss (2011). The median of the distribution of the values of the variables is the threshold for full non-membership (fuzzy value of 0.05 ) and the threshold for full-membership that is used to calibrate high outcome values is now used as the indifference point (that is, the $90^{\text {th }}$ percentile of the variables now corresponds to a fuzzy value of 0.5 ). As for the threshold for full membership (fuzzy value of 0.95), Fiss (2011) uses a very high value for which he does not present a percentile, so we chose a high percentile, the $95^{\text {th }}$ percentile, of the distribution of values. The calibration of low outcome values (LoRep and LoCBI) also draws on Fiss (2011). The median is the threshold for full non-membership and a very low value (the $10^{\text {th }}$ percentile in our case) is used as the threshold for full membership. For the indifference point, 
Fiss (2011) uses a value that is halfway between the full membership and the full nonmembership thresholds, while we choose a percentile that is halfway between those thresholds, specifically, the $30^{\text {th }}$ percentile.

In the case of sex, females were codified as 1 and males as 0 . For age, the same logic was applied as with the constructs that are presented above: the $90^{\text {th }}$ percentile (age 34) was used as the threshold for full membership, the $10^{\text {th }}$ percentile (age 19) was the threshold for full nonmembership, and the median (age 22) was used as the indifference point. Regarding Reg, regular drinkers (that is, those who drink at least once a week) were codified as 1 , and occasional drinkers (who drink less than once per week) as 0.

\subsubsection{Consistency and frequency thresholds}

The use of fsQCA requires the definition of two thresholds: a frequency threshold and a consistency threshold. The frequency threshold establishes the minimum number of cases that should belong to a given configuration for that configuration to be included in the causal analysis. When the total number of cases is small, and the researcher has intimate knowledge of those cases, a low threshold of one or two cases is often used; however, when the total number of cases is large, and there is little knowledge of individual cases, it is advisable to use a larger threshold because those low-frequency configurations might represent random forces or measurement errors (Ragin \& Fiss, 2008). To our knowledge, there are no explicit rules for the selection of a frequency threshold: the choice is based on a trade-off between the potential for deductive analysis and the inclusion of rare configurations (Emmenegger et al., 2014). In this application, given the large number of cases and the homogeneity of the sample, we decided to use a frequency threshold of 6 , so that the included configurations would not be "rare," but we 
did not leave out possibly relevant information. Given the importance of this threshold, and the fact that other choices might also be defensible, we performed a robustness analysis concerning its choice (see Appendix II), and we concluded that different choices did not lead to significant changes in the results.

The consistency measures how strongly the empirical evidence supports the argument that a given causal combination is a subset of the outcome, and the consistency threshold is the minimum consistency that is required to consider that a given configuration leads to the presence of the outcome in the causal analysis. For the choice of a consistency threshold, several authors recommend avoiding values that are less than 0.75 and preferably using values of 0.80 or higher (e.g., Ragin, 2009, p.121). To choose a specific value, the most recommended procedure consists of identifying substantial gaps in the range of the consistency scores for the combinations to be used in the causal analysis (e.g., Ragin, 2009, p.121). These criteria led us to use a consistency threshold of 0.80 for both HRep and HCBI: for HRep, we have a gap between 0.788 and 0.827 , and all of the other gaps above 0.80 are much smaller; for HCBI, we have a gap between 0.788 and 0.818 , and the only other sizeable gap above 0.80 left few configurations above the threshold. Additionally, we also note that a consistency threshold of 0.80 is common in the literature (e.g., Ragin \& Fiss, 2008; Navarro et al., 2016). In spite of having quite strong reasons for choosing this value, we also performed a robustness analysis of the choice of this threshold and concluded that alternative values led to different solutions but not significantly (see Appendix II).

\subsubsection{Analysis of necessary conditions}


According to Schneider and Wagemann (2010) the number of conditions should be reduced, and the analysis of necessary and sufficient conditions should be done separately, starting with the analysis of necessary conditions. To evaluate the necessary conditions, Ragin (2008) proposed two criteria: the consistency and trivialness of the necessity.

The relationship between sex, age, and Reg and HCBI (outcome) was not clearly defined at the outset. Consequently, for these conditions, both presence and absence were considered to be possible necessary conditions (the tilde - negation - represents the absence of the condition). However, for BSS, BSB, BI, and MBE, only their presence was analyzed because it did not seem to be sensible to assume that their absence might contribute to HCBI. A similar analysis was performed for VHCBI and LoCBI. In this latter case, the absence of BSS, BSB, BI, and MBE was also included in the analysis. The same analysis was conducted for the fuzzy variables that are related to repurchase intentions (HRep, VHRep, LoRep). A summary of the results is presented in Table 1 and Table 2, respectively.

\section{(Insert Table 1 about here)}

(Insert Table 2 about here)

It is usually recommended that the consistency threshold that is used to assess necessary conditions should be larger than that which is used for sufficient conditions. In this study, we use a threshold of 0.9 (see, for example, Schneider et al., 2010). Tables 1 and 2 show that, in all cases, both the presence and the absence of age, sex, and Reg, show consistency levels that are much lower than this threshold. However, BSS, BSB, BI, and MBE show high consistency levels for VHCBI, and BSS, BI and HCBI show high consistency levels as necessary conditions for 
VHRep. For HCBI and LoCBI, no conditions reach the defined necessity threshold. However, the consistency levels for BSS, BI, BSB and MBE, in the case of $\mathrm{HCBI}$, and for their negation, in the case of LoCBI, are much higher than those that are related to age, sex and Reg. For HRep, no conditions reach the defined necessity threshold and, for LoRep, only the absence of HCBI reaches it. Again, the consistency levels for BSS, BI, BSB, MBE and HCBI, in the case of HRep, and their negation, in the case of LoRep, are much higher than those that are related to age, sex and Reg. All of the conditions that were found to be necessary show a non-negligible coverage; therefore, they are not trivial (see, for example, Schneider et al., 2010).

\section{Results}

This section reports the results of the configurational analysis for the outcomes of interest (the different levels of CBI and Rep), and it also addresses the predictive validity of the configurations. In the context of fsQCA, predictive validity is an important issue: in fact, most of the studies only report the model's fit validity (Wu, Yeh, \& Woodside, 2014); however, good fit does not necessarily mean that the models enable good predictions.

The notation that is used in the solution tables follows Fiss (2011): black circles ("•) indicate the presence of a condition; circles with a cross-out (" $\otimes$ ") indicate its absence (in fact, the absence of a causal condition is never a part of any configuration that is obtained in this research); blank spaces indicate a situation in which the causal condition may be either present or absent; large circles indicate core conditions, and small circles indicate peripheral conditions.

\subsection{Configurational analysis}


In the configurational analysis, both the parsimonious solution and the intermediate solution, which includes only theoretically plausible counterfactuals, were considered. In the intermediate solution, it was defined that only the presence of the antecedents should contribute to the outcome (not their absence). According to Fiss (2011, p. 403) "core conditions are those that are part of both parsimonious and intermediate solutions, and peripheral conditions are those that are eliminated in the parsimonious solution and thus only appear in the intermediate solution."

Independent analyses were performed for the different outcome levels (high, very high and low), because different conditions could be sufficient for different outcome levels. However, in all of the analyses concerning low and very high levels of CBI and Rep, the results for consistency were always below the predefined consistency cutoff threshold of 0.80 . Thus, the results suggest that there is no combination of conditions that leads to VHCBI, LoCBI, VHRep, and LoRep, although all of the conditions are considered to be necessary to achieve VHCBI, and most of them are necessary for VHRep (see Tables 1 and 2). Therefore, the subsequent analysis is focused on HCBI and HRep. The configurations to achieve HCBI and HRep are presented in Tables 3 and 4 .

(Insert Table 3 about here)

(Insert Table 4 about here)

For HCBI, the results show that all of the conditions are core because the intermediate and parsimonious solutions are identical. The consistency of the configurations (models) is always above 0.85 , and the raw coverage is above 0.65 , which indicates acceptable consistency and coverage. In terms of overall coverage, the combined models account for approximately 
$87 \%$ of membership in the outcome (HCBI). Table 3 shows that the presence of two conditions could lead to HCBI; however, either BSB or MBE should be part of the solution. In fact, the only combination that is missing is the one that joins BSS and BI, which suggests that the presence of cognitive antecedents alone is not sufficient to obtain HCBI, i.e., one affective antecedent should be necessary to obtain HCBI.

Table 4 shows the possible configurations to achieve HRep. As in the case of HCBI, all of the conditions are core. The results in the four models exhibit acceptable consistency $(>0.80)$ and coverage $(>0.60)$. The overall coverage indicates that the combined models account for approximately $92 \%$ of membership in the outcome of interest (HRep). The results indicate the existence of two distinct configurational groupings to repurchase intent. First, the presence of HCBI alone is sufficient to achieve HRep, which confirms the importance of HCBI to enhance repurchase intent. Second, models 2, 3, and 4, indicate combinations of some CBI antecedents that could also lead to HRep. It is important to highlight solution 2 (BSS*BI $\rightarrow$ HRep). Although the combined cognitive antecedents of CBI (i.e., BSS and BI) are not sufficient to achieve HCBI, they could be sufficient to achieve HRep. The third model shows that BI and BSB could lead to HRep, which is not surprising because they lead to HCBI, and HCBI appears to be sufficient to achieve HRep. Finally, the fourth model shows that MBE alone could also lead to HRep, which stresses the importance for brands to generate memorable brand experiences.

\subsection{Predictive validity}

Model validation with entire samples may suffer from aggregation bias (Yeh, Wang, \& Yieh, 2016), which could lead to misleading indications for marketing management. In fact, a good model fit does not necessarily mean that the model offers good predictions (Wu et al., 2014). 
To test for predictive validity, the sample was split into a modeling subsample and a holdout subsample, as has been suggested in the previous research (e.g., Xu, Zheng, Xu, \& Wang, 2016). Additionally, the roles of the subsamples were reversed, and the latter was treated as the modeling subsample and the former as the holdout subsample. The assignment of the observations to the subsamples was completely random, and it was performed in such a way that the two subsamples would have the same number of observations (in fact, subsample 1 has one observation more than subsample 2, 587 versus 586 , because the total number of observations is odd). The objective of the test is to determine whether the model that is obtained from subsample 1 has high predictive ability for subsample 2 , and vice versa. For this purpose, the models that are obtained from each subsample should perform well in the other subsample, i.e., they should have similar configurations, high consistency and coverage.

Table 5 shows the configurations to achieve HCBI. The model that is obtained from subsample 1 leads to consistent results in subsample 2, regarding both levels of consistency and levels of coverage. The same is true when subsample 2 is used as the modeling subsample and subsample 1 as the holdout subsample, which shows predictive validity. In addition, configurations that were determined using subsample 1 are the same ones that were obtained with the whole sample, and the configurations that were obtained with subsample 2 are quite similar - there is only one solution missing, which reinforces the predictive validity.

\section{(Insert Table 5 about here)}

Table 6 shows the configurations for HRep, which has been determined by using each subsample, and their consistency and coverage in the other subsample. As in the previous 
analysis for HCBI, the levels of consistency and levels of coverage do not change much when the models that are obtained from a subsample are applied to the other subsample. These results provide support for predictive validity. Additionally, the model that is obtained from subsample 2 leads to the same configuration as the whole sample, and the model that is obtained from subsample 1 includes a few changes, but they are not significant, which also reinforces the predictive validity.

In conclusion, the results that are presented in Tables 5 and 6 indicate that models for subsample 1 have high predictive ability for subsample 2, and vice versa.

(Insert Table 6 about here)

\subsection{Application of the obtained models in other datasets}

The survey on which this research is based was conducted on undergraduate students. The ages of most of these students are in the range between 19 and 24 years. This means that some questions may be raised about whether the model is also applicable to older consumers. Additionally, the survey concerns only a beer brand, thus questions may also be raised about the applicability of the model to other types of products.

To obtain some indications about the generalizability of the findings, the models that are presented in Tables 3 and 4 were applied to two other datasets:

- The subset of students aged 30 years or more, from the initial survey (188 beer consumers). The results from this subset were intended to provide more information about whether the results would also hold when the sample was no longer composed of predominantly young consumers. 
- A set of 185 of customers from the airline carrier TAP who answered an online survey that was conducted between the $17^{\text {th }}$ of January and the $14^{\text {th }}$ of February of 2017 . A random sample was obtained with a survey that replicates the questions of the initial survey; however, they are applied to TAP. The use of this new sample was intended to provide some indications about the generalizability of the results not only to customers with a more diverse range of ages but also to other products.

The results that were obtained with the application of the models to these datasets are shown in Table 7.

\section{(Insert Table 7 about here)}

In the application of the HCBI model, we can see that the consistency values that were obtained for individual configurations are in the range $0.877-0.943$ for the subset of older students and in the range $0.840-0.890$ for the airline customer dataset. Thus, a high consistency is obtained in the new datasets for all of the original configurations. The overall consistency and coverage are similar to the original values (see Table 3) for the subset of older students. In the case of the airline customers, the consistency is slightly lower (0.777) than it was in the original analysis; however, it is still acceptable (in fact, it is higher than the consistency of 0.753 that we obtained for HRep in the original analysis). The overall coverage is larger for TAP airline customers than in the original analysis (0.903 in the former dataset, 0.873 in the original analysis). To summarize, all of the results indicate that the model that is shown in Table 3 is also applicable to both the subset of older clients and to the new set of results from the customers of TAP airline. 
For the HRep model, the consistency values that were obtained for the individual configurations are generally larger in the subset of older students than in the original analysis, and they are quite similar in the case of the survey to customers of TAP airline. the overall consistency and coverage are very similar to the original values for the customers of TAP airline. In the case of the subset of older students, the consistency is slightly higher $(0.787)$ than in the original analysis (0.753). The overall coverage is a little lower in the subset of older students than in the original analysis (0.929 in the former subset, 0.918 in the original analysis). Once again, all of the results indicate that the original model is also applicable to both the subset of older clients and the new set of results from the customers of TAP airline.

To summarize, the results that are presented in Table 7 indicate that the original models can be applied to both the subset of students aged 30 or more and to a sample of TAP customers.

\section{Discussion of the results}

Complexity theory recognizes that several combinations may cause the outcome of interest, and both theory and method are asymmetric in focus. The analysis of necessary conditions shows that neither the presence nor the absence of age, sex, and Reg are relevant for CBI and Rep, which focused the analysis on the chosen constructs. However, BSS, BSB, BI, and MBE (or their absence, in the case of LoCBI and LoRep) show high consistency levels (although they sometimes are below the defined necessity threshold).

The four antecedents of CBI (BSS, BI, BSB, MBE) are necessary for VHCBI (showing consistency levels above 0.94); however, no combination of them is sufficient to achieve the outcome of interest. Similarly, for VHRep, BSS, BI and CBI are necessary conditions, and BSB and MBE are almost necessary conditions; however, there is no configuration that consistently 
leads to this outcome. Thus, the results suggest that something more is needed to achieve a very high state of consumer identification and commitment to a brand, i.e., one that is on the right tail of the outcome distributions.

Regarding HCBI, five different configurations of sufficient conditions were found. All five solutions imply the joint presence of two conditions and thereby corroborate the first tenet. The raw coverage values that range from 0.65 to 0.73 (see Table 3 ) indicate that all of the causal configurations are more or less equally represented, and near $87 \%$ of the outcomes are explained by the presented configurations. Considering the unique coverage, the most important configuration is configuration $5(\mathrm{BSB} * \mathrm{MBE})$. These two conditions (BSB and $\mathrm{MBE}$ ) are the most frequent, and this has qualitative significance, indicating that affective drivers have more importance than cognitive drivers for obtaining HCBI. In fact, the mainly cognitive drivers of CBI, i.e., BSS and BI, only lead to HCBI in conjunction with a more affective driver (BSB or MBE); however, the reverse does not occur. This result is consistent with Stokburger-Sauer et al. (2012) who suggest a stronger role of affective antecedents; however, this is in contrast with the findings of Bhattacharya and Sen (2003) who show a major influence of cognitive drivers. These findings show different possible paths to $\mathrm{HCBI}$, thereby enabling brand managers to make better decisions on marketing investment allocation.

Regarding HRep, four different configurations were found. First, HCBI alone is sufficient to achieve HRep, which thereby corroborates the predictive power of CBI on consumers' willingness to expend additional effort to preserve and support a brand, which is recognized by the marketing literature (e.g., Bhattacharya \& Sen, 2003; He, Li \& Harris, 2012; Tuškej et al., 2013). However, HCBI is sufficient but not necessary for HRep. Thus, the second tenet is also supported. 
In fact, somewhat surprisingly, the most important solution is the combination of the BSS and BI conditions, with a unique coverage of 0.04 (see Table 4). This solution leads to high repurchase intentions without the presence of any affect-based driver of CBI. Thus, a brand can achieve high repurchase without establishing HCBI if brand-self similarity and brand identity simultaneously occur, i.e., for HRep a combination of only cognitive-based factors could be sufficient.

Another important finding is that MBE alone is a sufficient condition for HRep, which implies that a brand can create value through experiences (Cliffe \& Motion, 2005) and that brands can achieve greater purchase loyalty by appealing to consumers' fondness for the brand (Chaudhuri \& Holbrook, 2001) and creating memorable experiences that emotionally connect consumers to the brand (Schmitt, 2012). The construction of brand-related narratives and greater self-referencing could be associated with the consumption of certain brands, as has been noted by Stokburger-Sauer et al. (2012). In fact, narratives that are based on memorable brand experiences could generate affectively charged memories and build stronger connections between the consumer and the brand (Escalas, 2004).

As reported above, because HCBI is a necessary, but not sufficient, condition for VHRep, the third tenet is also supported. The results show that although HCBI is sufficient for obtaining HRep, it is not sufficient for VHRep. This is an interesting a new insight with practical implications. A growing number of brands are repositioning themselves to fit into the consumer's lifestyle; however, the results show that there are limits to the benefits of positioning brands as a means of self-expression. Therefore, brand managers could better allocate their resources with the knowledge that additional investments in CBI, when they already achieve high repurchase intentions, may not result in VHRep, i.e., the effect of CBI is not linear. In fact, 
no solutions were found for low Rep and low CBI, which contrasts with the results that were obtained for HRep and HCBI, i.e., the conditions for low values are not the mirror opposites of the conditions for high values of the outcomes of interest. Thus, the last tenet is also supported, which also validates the use of a fsQCA methodology in the marketing context.

\section{Conclusion and managerial implications}

Unlike most business research on CBI and Rep, which is based on symmetric thinking, this paper uses asymmetric analytics and contributes to complexity theory. The main fsQCA results indicate highly consistent configurational models that are sufficient for predicting high levels of CBI and Rep. The results suggest that not only are there different combinations of conditions that lead to the same outcomes but there are also some conditions that are not necessary to obtain them, which has important implications for marketing managers. Thus, the application of settheoretic methods, such as fsQCA, which treat configurations as different types of cases, rather than the conventional variable-based approach methods, constitutes an opportunity to advance research contributions for theory building and practice.

The obtained results contribute to advancing brand identification theory in several ways. First, different configurations of CBI drivers could be used to achieve high CBI, which indicates that the presence of all of the antecedents that have been suggested in the literature are not essential to achieve the outcome of interest. Second, affective-based drivers must be present to achieve high CBI, which reinforces the importance of this category. Third, high CBI is a sufficient condition for high Rep, but it is not necessary; in fact, either the combination of the two cognitive-based drivers $(\mathrm{BSS} * \mathrm{BI})$ or the existence of memorable brand experiences are sufficient to obtain high Rep. 
Building on these insights, some managerial implications should be highlighted. Brand managers can choose different paths to high CBI or high Rep and thereby focus their investments and improve their efficiency and effectiveness. The consumer-brand interactions assume an important role in CBI formation, and opportunities for socialization among consumers should be promoted to enable positive emotional links between the consumer and the brand. In fact, experiences are an increasingly important part of consumers' identities and, MBE per se may be sufficient to achieve high repurchase intentions. Thus, brands should create superior consumption experiences and invest in developing brand communities to enhance both CBI and Rep. Nevertheless, the joint presence of BI and BSS also leads to the same outcome. Thus, an investment in communications that build both distinctiveness and prestige, and thereby enhance brand identity and create a brand personality that matches consumers' self-concept and fulfills consumers need for consistency, could be sufficient to achieve high repurchase intentions. This requires a deep understanding of the targeted customers' lifestyles and preferences to communicate and project adequate elements of identity.

We must acknowledge that this research is not without limitations. For practical reasons, this study resorts to a cross-sectional survey that is based on answers that use a 7-point scale. As noted by Woodside (2016), the use of 7-point scales leads to weaknesses in the quality of data, as well as a lack of a dynamic assessment of the behavior of the respondents. The main analysis is conducted on a single product (beer) and brand (Sagres), and it was performed on a student sample from a single country (Portugal). The analysis of the behavior of the obtained models in a subset of older students and in a sample of airline customers gives us some confidence regarding the generalizability of the results; however, we acknowledge that a more diverse set of products 
and brands, and a broader sample of respondents that would include other countries, would provide additional robustness to the results.

To overcome some of these limitations, we suggest that future research should consider a more diverse set of products and brands, and a broader sample of respondents. Moreover, we strongly recommend a dynamic study that is based on interviewing a limited sample of respondents over a period of time to capture not only intentions but also the actual behavior. 


\section{References}

Aaker, J. L. (1997). Dimensions of brand personality. Journal of Marketing Research, $34,347-356$.

Ahearne, M., Bhattacharya, C. B., \& Gruen, T. (2005). Antecedents and consequences of customer-company identification: Expanding the role of relationship marketing. Journal of Applied Psychology, 90, 574-585.

Ali, M., Kan, K. A. S., \& Sarstedt, M. (2016). Direct and configurational paths of absorptive capacity and organizational innovation to successful organizational performance. Journal of Business Research, 69, 5317-5323.

Atilgan, E., Aksoy, S., \& Akinci, S. (2005). Determinants of the brand equity: A verification approach in the beverage industry in Turkey. Marketing Intelligence and Planning, 23, 237-248.

Baek, T. H., Kim, J., \& Yu, J. H. (2010). The differential roles of brand credibility and brand prestige in consumer brand choice. Psychology and Marketing, 27, 662678.

Bergami, M., \& Bagozzi, R. P. (2000). Self-categorization, affective commitment, and group self-esteem as distinct aspects of social identity in the organization. British Journal of Social Psychology, 39, 555-577.

Bhattacharya, C. B. \& Sen, S. (2003). Consumer-company identification: A framework for understanding consumers' relationships with companies. Journal of Marketing, 67, 76-88.

Buil, I., Chernatony, L., \& Martínez, E. (2013). Examining the role of advertising and sales promotions in brand equity creation. Journal of Business Research, 66, 115-122.

Chai, J. C. Y., Malhotra, N. K., \& Alpert, F. (2015). A two-dimensional model of trustvalue-loyalty in service relationships, Journal of Retailing and Consumer Services, 26, 23-31.

Chaudhuri, A. \& Holbrook, M. B. (2001). The chain of effects from brand trust and brand affect to brand performance: The role of brand loyalty. Journal of Marketing, 65, 81-93.

Chernev, A., Hamilton, R., \& Gal, D. (2011). Competing for consumer identity: Limits to self-expression and the perils of lifestyle branding. Journal of Marketing, 75, 66-82.

Cliffe, S. J. \& Motion, J. (2005). Building contemporary brands: A sponsorship-based 
strategy. Journal of Business Research, 58, 1068-1077.

Cobb-Walgren, C. J., Ruble, C. A., \& Donthu, N. (1995). Brand equity, brand preference, and purchase intent. Journal of Advertising, 24, 25-40.

Elbedweihy, A., Jayawardhena, C., Elsharnouby, M. H., \& Elsharnouby, T. H. (2016). Customer relationship building: The role of brand attractiveness and consumerbrand identification. Journal of Business Research, 69, 2901-2910.

Emmenegger, P., Schraff, D., \& Walter, A. (2014). QCA, the truth table analysis and large-N survey data: The benefits of calibration and the importance of robustness tests. Compass Working Paper 2014-79, available at http://www.compasss.org/wpseries/ $\quad$ EmmeneggerSchraffWalter2014.pdf (Accessed 24.03.2016)

Escalas, J. (2004). Narrative processing: Building consumer connections to brands. Journal of Consumer Psychology, 14, 168-180.

Fiss, P. C. (2007). A set-theoric approach to organizational configurations. Academy of Management Review, 32, 1190-1198.

Fiss, P. C. (2011). Building better causal theories: A fuzzy set approach to typologies in organization research. Academy of Management Journal, 54, 393-420.

Greckhamer, T., Misangyi, V. F., \& Fiss, P. C. (2013). The Two QCAs: From a Small$\mathrm{N}$ to a Large-N Set Theoretic Approach. In P. C. Fiss, B. Cambré, \& A. Marx (Eds.), Configurational Theory and Methods in Organizational Research (pp. 49-75). Emerald Group Publishing Limited.

He, H., Li, Y., \& Harris, L. (2012). Social identity perspective on brand loyalty. Journal of Business Research, 65, 648-657.

Ho, J., Plewa, C., \& Lu, V. N. (2016). Examining strategic orientation complementarity using multiple regression analysis and fuzzy set QCA. Journal of Business Research, 69, 2199-2205.

Kuenzel, S. \& Halliday, S. V (2008). Investigating antecedents and consequences of brand identification. Journal of Product and Brand Management, 17, 293-304.

Kuenzel, S. \& Halliday, S. V. (2010). The chain of effects from reputation and brand personality congruence to brand loyalty: The role of brand identification. Journal of Targeting, Measurement and Analysis for Marketing, 18, 167-176.

Lam, S. K., Ahearne, M., Mullins, R., Hayati, B., \& Schillewaert, N. (2013). Exploring the dynamics of antecedents to consumer-brand identification with a new brand. Journal of the Academy of Marketing Science, 41, 234-252. 
Mazodier, M. \& Merunka, D. (2012). Achieving brand loyalty through sponsorship: The role of fit and self-congruity. Journal of the Academy of Marketing Science, $40,807-820$.

Navarro, S., Llinares, C., \& Garzon, D. (2016). Exploring the relationship between cocreation and satisfaction using QCA. Journal of Business Research, 69, 13361339.

Nyadzayo, M. \& Khajehzadeh, S. (2016). The antecedents of customer loyalty: A moderated mediation model of customer relationship management quality and brand image. Journal of Retailing and Consumer and Consumer Services, 30, 262-270.

O'Cass, A. \& Frost, H. (2002). Status brands: Examining the effects of non-productrelated brand associations on status and conspicuous consumption. Journal of Product and Brand Management, 11, 67-88.

Ordanini, A., Parasuraman, A., \& Rubera, G. (2014). When the recipe is more important than the ingredients a Qualitative Comparative Analysis (QCA) of service innovation configurations. Journal of Service Research, 17, 134-149.

Park, C. W., MacInnis, D. J., Priester, J., Eisingerich, A. B., \& Iacobucci, D. (2010). Brand attachment and brand attitude strength: Conceptual and empirical differentiation of two critical brand equity drivers. Journal of Marketing, 74, 117.

Raghunathan, R., Naylor, R. W., \& Hoyer, W. D. (2006). The unhealthy = tasty intuition and its effects on taste inferences, enjoyment, and choice of food products. Journal of Marketing, 70, 170-184.

Ragin, C. C. (2008). Redesigning social inquiry: Fuzzy sets and beyond. Chicago: University of Chicago Press.

Ragin, C. C. (2009). Qualitative Comparative Analysis Using Fuzzy Sets (fsQCA). In C. C. Ragin, \& B. Rihoux (Eds.), Configurational Comparative Methods: Qualitative Comparative Analysis (QCA) and Related Techniques (pp. 87-122). Los Angeles: Sage.

Ragin, C. C., \& Fiss, P. C. (2008). Net effects analysis versus configurational analysis: An empirical demonstration. In C. C. Ragin (Eds.), Redesigning social inquiry: Fuzzy sets and beyond (pp. 190-212). Chicago: University of Chicago Press.

Rihoux, B. (2006). Qualitative comparative analysis (QCA) and related systematic comparative methods recent advances and remaining challenges for social science research. International Sociology, 21, 679-706. 
Rihoux, B., \& Marx, A. (2013). QCA, 25 years after "The Comparative Method": Mapping, Challenges, and Innovations - Mini-Symposium. Political Research Quarterly, 66, 167-235.

Ryan, J. C., \& Berbegal-Mirabent, J. (2016). Motivational recipes and research performance: A fuzzy set analysis of the motivational profile of high performing research scientists. Journal of Business Research, 69, 5299-5304.

Schmitt, B. (2012). The consumer psychology of brands. Journal of Consumer Psychology, 22, 7-17.

Schneider, M. R., \& Eggert, A. (2014). Embracing complex causality with the QCA method: An invitation. Journal of Business Market Management, 7, 312-328.

Schneider, M. R., Schulze-Bentrop, C., \& Paunescu, M. (2010). Mapping the institutional capital of high-tech firms: A fuzzy-set analysis of capitalist variety and export performance. Journal of International Business Studies, 41, 246-266.

Schneider, C. Q., \& Wageman, C. (2010). Standards of Good Practice in Qualitative Comparative Analysis (QCA) and Fuzzy-Sets. Comparative Sociology, 9, 397418.

Sirgy, M. J., Lee, D-J., Johar, J. S., \& Tidwell, J. (2008). Effect of self-congruity with sponsorship on brand loyalty. Journal of Business Research, 61, 1091-1097.

Sirgy, M. J. (1985). Using self-congruity and ideal congruity to predict purchase motivation. Journal of Business Research, 13, 195-206.

Skaaning, S. E. (2011). Assessing the robustness of crisp-set and fuzzy-set QCA results. Sociological Methods \& Research, 40, 391-408.

So, K., King, C., Hudson, S., \& Meng, F. (2017). The missing link in building customer brand identification: The role of brand attractiveness. Tourism Management, 59, 640-651.

Steenkamp, J-B., Batra, R., \& Alden, D. L. (2003). How perceived brand globalness creates brand value. Journal of International Business Studies, 34, 53-65.

Stokburger-Sauer, N., Ratneshwar, S., \& Sen, S. (2012). Drivers of consumer-brand identification. International Journal of Research in Marketing, 29, 406-418.

Thompson, C. J., Rindfleisch, A., \& Arsel, Z. (2006). Emotional branding and the strategic value of the doppelgänger brand image. Journal of Marketing, 70, 5064. 
Torres, P. M., Augusto, M. G., \& Lisboa, J. V. (2015). Determining the causal relationships that affect consumer-based brand equity. Marketing Intelligence and Planning, 33, 944-956.

Tuškej, U., Golob, U., \& Podnar, K. (2013). The role of consumer-brand identification in building brand relationships. Journal of Business Research, 66, 53-59.

Vis, B. (2012). The comparative advantages of fsQCA and regression analysis for moderately large-N analyses. Sociological Methods \& Research, 41, 168-198.

Wolter, J. S., Brach, S., Cronin Jr., J. J., \& Bonn, M. (2016). Symbolic drivers of consumer-brand identification and disidentification. Journal of Business Research, 69, 785-793.

Woodside, A. G. (2012). Proposing a new logic for data analysis in marketing and consumer behavior: Case study research of large-N survey data for estimating algorithms that accurately profile $\mathrm{X}$ (extremely high-use) consumers. Journal of Global Scholars of Marketing Science, 22, 277-289.

Woodside, A. G. (2013). Moving beyond multiple regression analysis to algorithms: Calling for the adoption of a paradigm shift from symmetric to asymmetric thinking in data analysis and crafting theory. Journal of Business Research, 66, 463-472.

Woodside, A. G. (2014). Embrace*perform*model: Complexity theory, contrarian cases analysis, and multiple realities. Journal of Business Research, 67, 2495-2503.

Woodside, A. G. (2016). The good practices manifesto: Overcoming bad practices pervasive in current research in business. Journal of Business Research, 69, 365381.

Wu, P. L., Yeh, S. S., \& Woodside, A. G. (2014). Applying complexity theory to deepen service dominant logic: Configural analysis of customer experience-andoutcome assessments of professional services for personal transformations. Journal of Business Research, 67, 1647-1670.

Wyllie, J., Carlson, J., \& Rosenberger, P. (2014). Examining the influence of different levels of sexual-stimuli intensity by gender on advertising effectiveness. Journal of Marketing Management, 30, 697-718.

Xu, B., Zheng, H., Xu, Y., \& Wang, T. (2016). Configurational paths to sponsor satisfaction in crowdfunding. Journal of Business Research, 69, 915-927.

Yeh, C-H., Wang, Y-S., \& Yieh, K. (2016). Predicting smartphone brand loyalty: Consumer value and consumer-brand identification perspectives. International Journal of Information Management, 36, 245-257. 
Yoo, B., Donthu, N., \& Lee, S. (2000). An examination of selected marketing mix elements and brand equity. Journal of the Academy of Marketing Science, 28, 195-211.

Zawrun, L., Linz, D., Metzger, M., \& Kunkel, D. (2006). Effects of showing risk in beer commercials to young drinkers. Journal of Broadcasting and Electronic Media, $50,52-77$. 


\section{Appendix I. Scale items and Cronbach's alpha coefficients}

\begin{tabular}{|c|c|c|}
\hline Construct & Items & Cronbach's $\alpha$ \\
\hline $\begin{array}{l}\text { Brand-self } \\
\text { Similarity }\end{array}$ & $\begin{array}{l}\text { Sincere (e.g., Down-to-earth, honest, genuine) } \\
\text { Exciting (e.g., Daring, spirited, young, up-to-date) } \\
\text { Competent (e.g., Reliable, efficient, leader) } \\
\text { Sophisticated (e.g., Glamorous, charming, upper class) } \\
\text { Rugged (e.g., Tough, strong, outdoorsy) }\end{array}$ & .95 \\
\hline $\begin{array}{l}\text { Brand } \\
\text { Identity }\end{array}$ & $\begin{array}{l}\text { Brand Sagres is very prestigious } \\
\text { Brand Sagres is one of the best brands of beer } \\
\text { Brand Sagres is a first-class, high quality brand } \\
\text { Brand Sagres is unique } \\
\text { Brand Sagres stands out from its competitors }\end{array}$ & .91 \\
\hline $\begin{array}{l}\text { Brand social } \\
\text { Benefits }\end{array}$ & $\begin{array}{l}\text { Brand Sagres offers me the opportunity to socialize } \\
\text { I feel a sense of kinship with other people who use brand } \\
\text { Sagres } \\
\text { I gain a lot from interactions with other customers/users of } \\
\text { brand Sagres } \\
\text { Being a customer of brand Sagres makes me feel like I } \\
\text { belong to a special group } \\
\text { Brand Sagres creates warm feelings among its users }\end{array}$ & .92 \\
\hline $\begin{array}{l}\text { Memorable } \\
\text { brand } \\
\text { experiences }\end{array}$ & $\begin{array}{l}\text { I have had a lot of memorable experiences with brand } \\
\text { Sagres } \\
\text { Thinking of brand Sagres brings back good memories } \\
\text { I have fond memories of brand Sagres }\end{array}$ & .95 \\
\hline $\begin{array}{l}\text { Consumer- } \\
\text { Brand } \\
\text { identification }\end{array}$ & $\begin{array}{l}\text { I feel a strong sense of belonging to brand Sagres } \\
\text { I identify strongly with brand Sagres } \\
\text { Brand Sagres embodies what I believe in } \\
\text { Brand Sagres is like a part of me } \\
\text { Brand Sagres has a great deal of personal meaning to me }\end{array}$ & .96 \\
\hline Repurchase & $\begin{array}{l}\text { I intend to buy the brand Sagres again } \\
\text { I would consider buying another products from brand } \\
\text { Sagres } \\
\text { When consuming beer again, I will continue to choose } \\
\text { brand Sagres }\end{array}$ & .89 \\
\hline
\end{tabular}




\section{Appendix II. Robustness analysis}

The robustness analysis was inspired by Skaaning (2011). We analyze how the configurations that we obtain are affected by different choices of the calibration thresholds, frequency threshold and consistency threshold. This robustness analysis was made only to the configurations that were defined to achieve HRep and HCBI because they are the main models of our study. The results, which are presented as changes in relation to the original configurations that are shown in Tables 3 and 4, are summarized in Table II.1.

\section{Changing the calibration thresholds}

In Subsection 3.2.3 we explain the original calibration that we used to reach the results that are presented in Tables 3 and 4: we used the direct calibration method, with the $90^{\text {th }}, 10^{\text {th }}$ and $50^{\text {th }}$ percentiles of the values of the original distribution of each variable being used to define the full membership threshold, non-membership threshold, and the crossover point, respectively. In our robustness analysis, we considered different percentiles in the definition of the thresholds:

Full membership threshold Non-membership threshold $\quad$ Cross-over point

Original calibration

Alternative 1

Alternative 2 $90^{\text {th }}$ percentile

$95^{\text {th }}$ percentile

$85^{\text {th }}$ percentile $10^{\text {th }}$ percentile

$5^{\text {th }}$ percentile

$15^{\text {th }}$ percentile $50^{\text {th }}$ percentile

$50^{\text {th }}$ percentile

$50^{\text {th }}$ percentile

The idea of these alternative thresholds is to keep the crossover point at the median (it seems the most reasonable choice), and considering full membership and non-membership thresholds to be further away from the median than the original ones (alternative 1) and closer to the median than the original ones (alternative 2). 
First, we changed the calibration of only one variable at a time. This was done both for the variable that was being explained and for the antecedent variables, for the models in Tables 3 and 4. In all of the cases the results were unaltered, which means that these alternative calibrations did not change the results.

Then, we changed all of the variables at the same time according to the thresholds that corresponded to alternatives 1 and 2. For the HRep model that is presented in Table 4, there was no change for any of the alternative calibrations. The HCBI model was not altered when the calibration of all of the variables were changed according to alternative 2 ; however, it was altered when changes were made according to alternative 1: the three configurations that involve MBE were replaced by a single configuration that consisted only of MBE - that is, MBE no longer needs another antecedent to lead to HCBI, but it alone becomes sufficient to reach HCBI.

We conclude that the results in Tables 3 and 4 are quite robust to changes in calibration because there is only one case in which there is a change, and the new model that we obtain is not very different from the original one.

\section{Changing the frequency thresholds}

As we explain above, the consistency thresholds were initially set to 6 . We started by changing these thresholds for alternative values that were close to the original: we chose 4 (a lower value seemed unreasonably small) and 9 (a 50\% increase). In the case of the HCBI model, these alternative thresholds do not change the configurations that were included in the analysis, thus the results were unchanged. In the case of HRep, the solution changes only for a frequency threshold of 4, as is shown in Table II.1. However, this change is quite small: a new 
configuration appears in the model, and the intersection of BSS and BSB is now sufficient for HRep.

We then tried a more substantial increase in this threshold. In choosing a new value for this threshold we aimed to strike a balance between a sizeable increase in the threshold and keeping a reasonable number of configurations with a frequency that was above the threshold. Some authors define a threshold that captures approximately $80 \%$ of the cases (see, for example Ragin \& Fiss, 2008). When it is applied to the HRep model, this rule leads to a threshold of 18 , keeping approximately $79 \%$ of the cases and 10 configurations above the threshold. The same threshold was applied to the HCBI model, keeping approximately 94\% of the cases and 12 configurations above the threshold. These new thresholds caused some changes in the results, as is shown in Table II.1. In the case of HCBI, the core conditions are not altered (the parsimonious solution is not changed); however, new peripheral conditions appear in four out of the five configurations. In the case of HRep, one of the original configurations disappears, and new peripheral conditions appear in two of the other three configurations.

\section{Changing the consistency thresholds}

For the consistency threshold, we looked for gaps in the distribution of the consistency values. For consistency values that were lower than 0.8 , we considered only gaps above 0.75 : as Ragin notes, “...values below 0.75 ... indicate substantial inconsistency...” (Ragin, 2008, p. 144). We chose an alternative threshold of 0.77 (gap between 0.762 and 0.788 for HCBI and gap between 0.749 and 0.788 for HRep). For values that were larger than 0.8 , we could find no sizeable gaps for HRep, and, for HCBI, a gap that existed at approximately 0.9 left few configurations above 
the gap. Thus, we ended up choosing a 0.83 threshold, which corresponds to a small gap (0.8180.832 for HCBI and 0.827-0.835 for HRep).

For HCBI, the new configurations that were obtained for the 0.77 and 0.83 thresholds are not very different from the original: for the 0.77 threshold, the three configurations that involved MBE were replaced by a single configuration that only consist of MBE; for the 0.83 threshold, the configuration that involves the intersection of BI and BSB no longer appears.

For HRep, the 0.77 threshold leads to replacing the two configurations that involve BI by a single one, consists only of BI: BI is now a sufficient condition, and it does not require another condition to be present. The 0.83 threshold replaces the configuration that consists of MBE by two new ones: the intersection of $\mathrm{MBE}$ and $\mathrm{BI}$ and the intersection of $\mathrm{MBE}$ and $\mathrm{BSB}$; $\mathrm{MBE}$ is no longer a sufficient condition; however, it requires that either BI or BSB also occur. 
Figure 1: Conceptual models.

Step 2

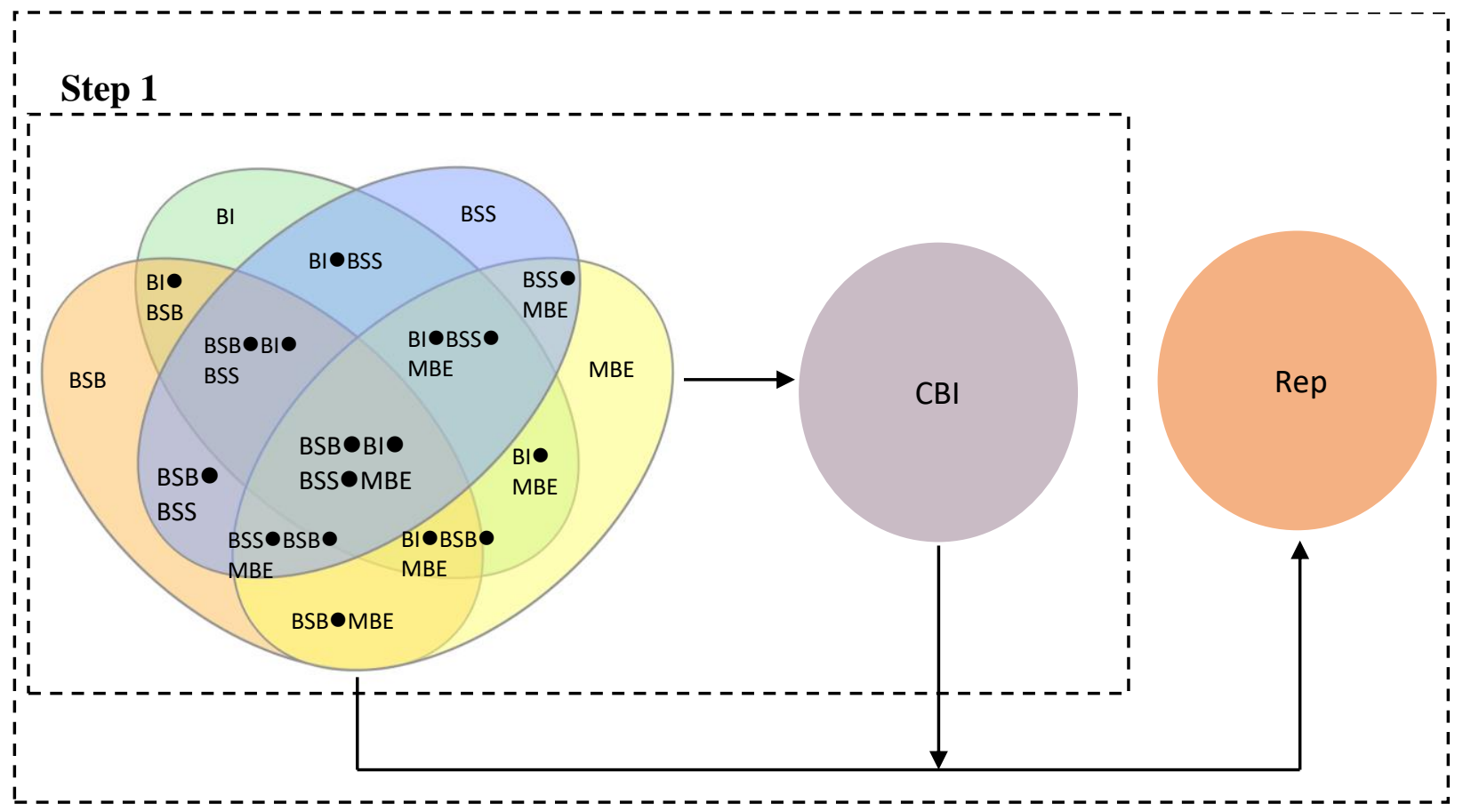

Note: Rep $=$ Repurchase intent, $\mathrm{CBI}=$ Consumer-brand identification, $\mathrm{BSS}=$ Brand-self similarity, BI $=$ Brand identity, $\mathrm{BSB}=\mathrm{Brand}$ social benefits, $\mathrm{MBE}=$ Memorable brand experiences . 
Table 1: Analysis of necessary conditions of CBI antecedents.

\begin{tabular}{|ccccccc|}
\hline & \multicolumn{2}{c}{ HCBI } & \multicolumn{2}{c}{ VHCBI } & \multicolumn{2}{c|}{ LoCBI } \\
\cline { 2 - 7 } & Consistency & Coverage & Consistency & Coverage & Consistency & Coverage \\
\hline BSS & 0.836 & 0.743 & 0.982 & 0.313 & 0.385 & 0.223 \\
$\sim$ BSS & - & - & - & - & 0.758 & 0.524 \\
BI & 0.761 & 0.733 & 0.947 & 0.328 & 0.372 & 0.234 \\
$\sim$ BI & - & - & - & - & 0.760 & 0.481 \\
BSB & 0.819 & 0.813 & 0.967 & 0.345 & 0.271 & 0.176 \\
$\sim$ BSB & - & - & - & - & 0.867 & 0.532 \\
MBE & 0.814 & 0.822 & 0.972 & 0.353 & 0.245 & 0.161 \\
$\sim$ MBE & - & - & - & - & 0.881 & 0.533 \\
Age & 0.559 & 0.576 & 0.651 & 0.241 & 0.552 & 0.372 \\
$\sim$ Age & 0.659 & 0.600 & 0.743 & 0.243 & 0.570 & 0.338 \\
Reg & 0.574 & 0.492 & 0.616 & 0.189 & 0.589 & 0.329 \\
$\sim$ Reg & 0.446 & 0.494 & 0.503 & 0.171 & 0.429 & 0.310 \\
Sex & 0.528 & 0.521 & 0.552 & 0.196 & 0.457 & 0.294 \\
$\sim$ Sex & 0.492 & 0.465 & 0.503 & 0.171 & 0.562 & 0.347 \\
\hline
\end{tabular}

Note: $\mathrm{BSS}=$ Brand-self similarity, $\mathrm{BI}=$ Brand identity, $\mathrm{BSB}=$ Brand social benefits, $\mathrm{MBE}=$ Memorable brand experiences, $\mathrm{HCBI}=$ High consumer-brand identification, $\mathrm{VHCBI}=$ Very high CBI, LoCBI $=$ Low CBI, Reg $=$ Regularity of beer consumption, and $\sim$ represents the absence of the condition. 
Table 2: Analysis of necessary conditions of Rep antecedents.

\begin{tabular}{|ccccccc|}
\hline & \multicolumn{2}{c}{ HRep } & \multicolumn{2}{c}{ VHRep } & \multicolumn{2}{c|}{ LoRep } \\
\cline { 2 - 7 } & Consistency & Coverage & Consistency & Coverage & Consistency & Coverage \\
\hline BSS & 0.826 & 0.778 & 0.944 & 0.323 & 0.404 & 0.223 \\
$\sim$ BSS & - & - & - & - & 0.798 & 0.526 \\
BI & 0.807 & 0.824 & 0.966 & 0.359 & 0.322 & 0.193 \\
$\sim$ BI & - & - & - & - & 0.866 & 0.522 \\
BSB & 0.729 & 0.768 & 0.846 & 0.324 & 0.361 & 0.223 \\
$\sim$ BSB & - & - & - & - & 0.834 & 0.488 \\
MBE & 0.764 & 0.818 & 0.881 & 0.343 & 0.304 & 0.191 \\
$\sim$ MBE & - & - & - & - & 0.871 & 0.502 \\
HCBI & 0.771 & 0.817 & 0.900 & 0.347 & 0.282 & 0.175 \\
$\sim$ HCBI & - & - & - & - & 0.908 & 0.528 \\
VHCBI & - & - & 0.617 & 0.662 & - & - \\
LoCBI & - & - & - & - & 0.686 & 0.654 \\
Age & 0.582 & 0.637 & 0.667 & 0.265 & 0.547 & 0.351 \\
$\sim$ Age & 0.632 & 0.610 & 0.692 & 0.242 & 0.622 & 0.352 \\
Reg & 0.549 & 0.499 & 0.569 & 0.188 & 0.617 & 0.328 \\
$\sim$ Reg & 0.469 & 0.551 & 0.474 & 0.202 & 0.404 & 0.278 \\
Sex & 0.528 & 0.552 & 0.571 & 0.217 & 0.457 & 0.280 \\
$\sim$ Sex & 0.491 & 0.492 & 0.474 & 0.173 & 0.564 & 0.332 \\
\hline
\end{tabular}

Note: BSS = Brand-self similarity, BI = Brand identity, BSB $=$ Brand social benefits, MBE = Memorable brand experiences, $\mathrm{HCBI}=$ High consumer-brand identification, $\mathrm{VHCBI}=$ Very high CBI, LoCBI $=$ Low CBI, Reg $=$ Regularity of beer consumption, HRep $=$ High repurchase intentions, VHRep $=$ Very high Rep, LoRep $=$ Low Rep, and $\sim$ represents the absence of the condition. 
Table 3: Configurations to achieve HCBI.

\begin{tabular}{|c|c|c|c|c|c|}
\hline \multirow[b]{2}{*}{ Configuration } & \multicolumn{5}{|c|}{ Solution } \\
\hline & 1 & 2 & 3 & 4 & 5 \\
\hline \multicolumn{6}{|l|}{ BSS } \\
\hline \multicolumn{6}{|l|}{ BI } \\
\hline \multicolumn{6}{|l|}{ BSB } \\
\hline MBE & & & & & \\
\hline Consistency & 0.883 & 0.878 & 0.883 & 0.880 & 0.902 \\
\hline $\begin{array}{l}\text { Raw coverage } \\
\text { Unique }\end{array}$ & 0.714 & 0.729 & 0.651 & 0.673 & 0.716 \\
\hline coverage & 0.020 & 0.013 & 0.010 & 0.010 & 0.037 \\
\hline $\begin{array}{l}\text { Overall solution } \\
\text { consistency }\end{array}$ & & 0.810 & & & \\
\hline Overall solution & overage & 0.873 & & & \\
\hline
\end{tabular}


Table 4: Configurations to achieve HRep.

\begin{tabular}{lcccc}
\hline & \multicolumn{4}{c}{ Solution } \\
Configuration & 1 & 2 & 3 & 4 \\
\hline HCBI & - & & & \\
BSS & & & & \\
BI & & - & - & \\
BSB & & & - & \\
MBE & & & & 0.818 \\
$\begin{array}{l}\text { Consistency } \\
\text { Raw coverage }\end{array}$ & 0.817 & 0.874 & 0.890 & 0.771 \\
$\begin{array}{l}\text { Unique } \\
\text { coverage }\end{array}$ & 0.722 & 0.619 & 0.764 \\
& 0.033 & 0.040 & 0.009 & 0.031
\end{tabular}

Overall solution consistency

Overall solution coverage $\quad 0.918$

Note: $\overline{\text { HRep }=\text { High repurchase intentions, HCBI }=\text { High consumer-brand identification, }}$ BSS = Brand-self similarity, $\mathrm{BI}=$ Brand identity, $\mathrm{BSB}=$ Brand social benefits, $\mathrm{MBE}=$ Memorable brand experiences. Black circles indicate the presence of a condition; blank spaces indicate "don't care". All conditions are core. 
Table 5: Configurations to achieve HCBI in the subsamples.

\begin{tabular}{|c|c|c|c|c|c|c|c|c|c|}
\hline \multirow[b]{3}{*}{ Configuration } & \multicolumn{5}{|c|}{ Configurations obtained from subsample 1} & \multicolumn{4}{|c|}{ Configuration obtained from subsample 2} \\
\hline & \multicolumn{5}{|c|}{$\begin{array}{l}\text { Solution } \\
\end{array}$} & \multicolumn{4}{|c|}{$\begin{array}{l}\text { Solution } \\
\end{array}$} \\
\hline & 1 & 2 & 3 & 4 & 5 & 1 & 2 & 3 & 4 \\
\hline \multicolumn{10}{|l|}{ BSS } \\
\hline \multicolumn{10}{|l|}{$\mathrm{BP}$} \\
\hline \multicolumn{10}{|l|}{$\mathrm{BSB}$} \\
\hline \multirow[t]{2}{*}{ MBE } & & & & & & & & & \\
\hline & \multicolumn{5}{|c|}{ Consistency/coverage in subsample 1} & \multicolumn{4}{|c|}{ Consistency/coverage in subsample 2} \\
\hline Consistency & 0.875 & 0.885 & 0.880 & 0.890 & 0.905 & 0.890 & 0.886 & 0.870 & 0.898 \\
\hline \multirow[t]{4}{*}{ Raw coverage } & 0.688 & 0.719 & 0.635 & 0.668 & 0.703 & 0.739 & 0.667 & 0.677 & 0.729 \\
\hline & \multicolumn{2}{|c|}{ Overall consistency } & \multicolumn{3}{|l|}{0.811} & \multicolumn{2}{|c|}{ Overall consistency } & \multicolumn{2}{|l|}{0.818} \\
\hline & \multirow{2}{*}{\multicolumn{2}{|c|}{ Overall coverage }} & \multicolumn{3}{|l|}{0.865} & \multicolumn{2}{|c|}{ Overall coverage } & \multicolumn{2}{|l|}{0.872} \\
\hline & & & age in & bsampl & e 2 & Consiste & covera & in subs & nple 1 \\
\hline \multirow{4}{*}{$\begin{array}{l}\text { Consistency } \\
\text { Raw coverage }\end{array}$} & 0.890 & 0.871 & 0.886 & 0.870 & 0.898 & 0.875 & 0.880 & 0.890 & 0.905 \\
\hline & 0.739 & 0.738 & 0.667 & 0.677 & 0.729 & 0.688 & 0.635 & 0.668 & 0.703 \\
\hline & \multicolumn{2}{|c|}{ Overall consistency } & \multicolumn{3}{|l|}{0.809} & \multirow{2}{*}{\multicolumn{2}{|c|}{$\begin{array}{c}\text { Overall consistency } \\
\text { Overall coverage }\end{array}$}} & \multicolumn{2}{|l|}{0.819} \\
\hline & \multicolumn{2}{|c|}{ Overall coverage } & \multicolumn{3}{|l|}{0.881} & & & \multicolumn{2}{|l|}{0.848} \\
\hline
\end{tabular}


Table 6: Configurations to achieve HRep in the subsamples.

\begin{tabular}{|c|c|c|c|c|c|c|c|c|c|}
\hline \multirow[b]{3}{*}{ Configuration } & \multicolumn{5}{|c|}{ Configurations obtained from subsample 1} & \multicolumn{4}{|c|}{ Configurations obtained from subsample 2} \\
\hline & \multicolumn{5}{|c|}{$\begin{array}{l}\text { Solution } \\
\end{array}$} & \multicolumn{4}{|c|}{$\begin{array}{ll}\text { Solution } \\
\end{array}$} \\
\hline & 1 & 2 & 3 & 4 & 5 & 1 & 2 & 3 & 4 \\
\hline \multicolumn{10}{|l|}{ HCBI } \\
\hline \multicolumn{10}{|l|}{ BSS } \\
\hline \multicolumn{10}{|l|}{ BI } \\
\hline \multicolumn{10}{|l|}{$\mathrm{BSB}$} \\
\hline \multicolumn{10}{|l|}{ MBE } \\
\hline & \multicolumn{5}{|c|}{ Consistency/coverage in subsample 1} & \multicolumn{4}{|c|}{ Consistency/coverage in subsample 2} \\
\hline Consistency & 0.842 & 0.863 & 0.854 & 0.883 & 0.806 & 0.828 & 0.884 & 0.896 & 0.886 \\
\hline \multirow[t]{4}{*}{ Raw coverage } & 0.642 & 0.711 & 0.636 & 0.604 & 0.749 & 0.779 & 0.733 & 0.634 & 0.667 \\
\hline & \multicolumn{2}{|c|}{$\begin{array}{c}\text { Overall } \\
\text { consistency }\end{array}$} & \multicolumn{3}{|l|}{0.747} & \multicolumn{2}{|c|}{ Overall consistency } & \multicolumn{2}{|l|}{0.767} \\
\hline & \multicolumn{2}{|c|}{ Overall coverage } & \multicolumn{3}{|l|}{0.891} & \multicolumn{2}{|c|}{ Overall coverage } & 0.930 & \\
\hline & \multicolumn{5}{|c|}{ Consistency/coverage in subsample 2} & \multicolumn{4}{|c|}{ Consistency/coverage in subsample 1} \\
\hline Consistency & 0.863 & 0.884 & 0.867 & 0.896 & 0.886 & 0.806 & 0.863 & 0.883 & 0.806 \\
\hline \multirow[t]{3}{*}{ Raw coverage } & 0.676 & 0.733 & 0.677 & 0.634 & 0.667 & 0.763 & 0.711 & 0.604 & 0.749 \\
\hline & \multirow{2}{*}{\multicolumn{2}{|c|}{$\begin{array}{c}\text { Overall } \\
\text { consistency } \\
\text { Overall coverage }\end{array}$}} & 0.775 & & & \multirow{2}{*}{\multicolumn{2}{|c|}{$\begin{array}{c}\text { Overall consistency } \\
\text { Overall coverage }\end{array}$}} & 0.739 & \\
\hline & & & 0.915 & & & & & 0.905 & \\
\hline
\end{tabular}

Note: HRep = High repurchase intentions, HCBI = High consumer-brand identification, BSS = Brand-self similarity, BI = Brand identification, $\mathrm{BSB}=$ Brand social benefits, $\mathrm{MBE}=$ Memorable brand experiences. Black circles indicate the presence of a condition. Large circles indicate core conditions and small ones indicate peripheral conditions. Blank spaces indicate "don’t care". 
Table 7: Results obtained by applying the HCBI and HRep models to the subset of older students (30 years or more) and to the results of a survey to the customers of an airline (TAP).

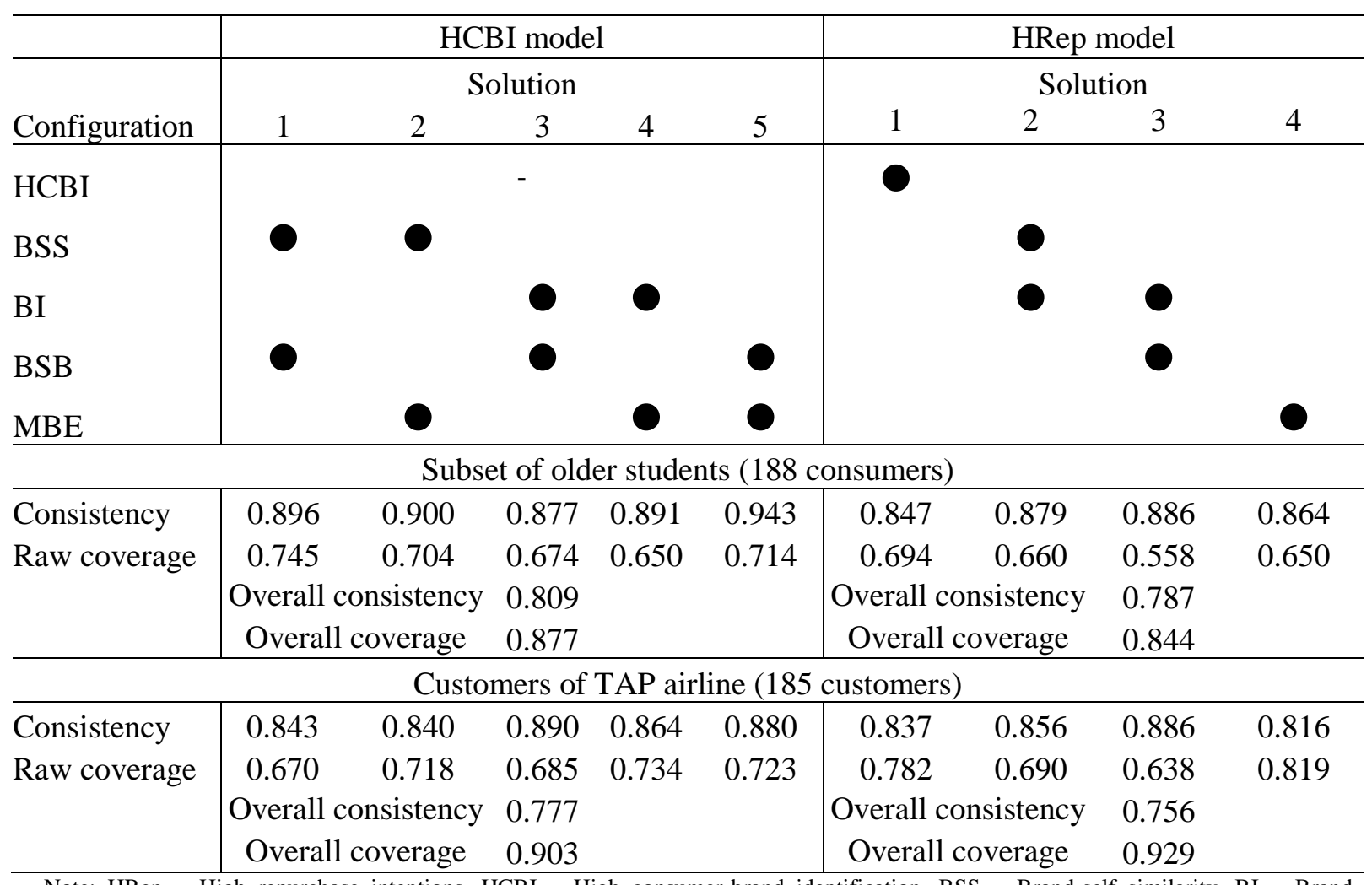

Note: HRep = High repurchase intentions, HCBI = High consumer-brand identification, BSS = Brand-self similarity, BI = Brand identification, $\mathrm{BSB}=$ Brand social benefits, $\mathrm{MBE}=$ Memorable brand experiences. Black circles indicate the presence of a condition; blank spaces indicate "don't care". All conditions are core. 
Table II.1: Changes in configurations obtained in the robustness analysis for HCBI and HRep, in relation to the original configurations (presented in Table 3 and Table 4, respectively).

\begin{tabular}{|c|c|c|c|}
\hline \multicolumn{4}{|l|}{ Robustness analysis for HCBI } \\
\hline Changes in thresholds & Changes in the solutions & $\begin{array}{c}\text { Overall } \\
\text { consistency }\end{array}$ & $\begin{array}{l}\text { Overall } \\
\text { coverage }\end{array}$ \\
\hline $\begin{array}{c}\text { Calibration of all variables } \\
\text { changed according to alternative } 1\end{array}$ & $\begin{array}{l}\text { Configurations } 2,4 \text { and } 5 \text { (the ones that } \\
\text { included MBE) replaced by a single } \\
\text { configuration consisting only of MBE }\end{array}$ & 0.788 & 0.886 \\
\hline $\begin{array}{c}\text { Calibration of all variables } \\
\text { changed according to alternative } 2\end{array}$ & No changes & 0.810 & 0.873 \\
\hline Frequency threshold set to 4 & No changes & 0.810 & 0.873 \\
\hline Frequency threshold set to 9 & No changes & 0.810 & 0.873 \\
\hline Frequency threshold set to 18 & $\begin{array}{l}\text { Peripheral condition BI included in } \\
\text { solutions } 1 \text { and 2, and peripheral condition } \\
\text { BSS included in solutions } 3 \text { and } 4\end{array}$ & 0.855 & 0.820 \\
\hline Consistency threshold set to 0.77 & $\begin{array}{l}\text { Configurations 2, } 4 \text { and } 5 \text { (the ones that } \\
\text { included MBE) replaced by a single } \\
\text { configuration that just includes MBE }\end{array}$ & 0.788 & 0.886 \\
\hline Consistency threshold set to 0.83 & Configuration 3 no longer appears & 0.823 & 0.863 \\
\hline \multicolumn{4}{|l|}{ Robustness analysis for HRep } \\
\hline Changes in thresholds & Changes in the solutions & $\begin{array}{c}\text { Overall } \\
\text { consistency }\end{array}$ & $\begin{array}{c}\text { Overall } \\
\text { coverage }\end{array}$ \\
\hline $\begin{array}{c}\text { Calibration of all variables } \\
\text { changed according to alternative } 1\end{array}$ & No changes & 0.753 & 0.918 \\
\hline $\begin{array}{c}\text { Calibration of all variables } \\
\text { changed according to alternative } 2\end{array}$ & No changes & 0.753 & 0.918 \\
\hline Frequency threshold set to 4 & $\begin{array}{l}\text { A new configuration appears, with BSB and } \\
\text { BSS as core conditions }\end{array}$ & 0.746 & 0.921 \\
\hline Frequency threshold set to 9 & No changes & 0.753 & 0.918 \\
\hline Frequency threshold set to 18 & $\begin{array}{l}\text { Configuration } 3 \text { no longer appears; } \\
\text { peripheral conditions BSB and MBE } \\
\text { included in solution 1; peripheral conditions } \\
\text { HCBI and BSB included in solution } 4\end{array}$ & 0.848 & 0.814 \\
\hline Consistency threshold set to 0.77 & $\begin{array}{c}\text { Configurations } 2 \text { and } 3 \text { (the ones that } \\
\text { included BI) replaced by a single } \\
\text { configuration consisting only of BI }\end{array}$ & 0.738 & 0.947 \\
\hline Consistency threshold set to 0.83 & $\begin{array}{l}\text { Configuration } 4 \text { (consisting only of MBE) } \\
\text { replaced by two new ones, one with core } \\
\text { conditions MBE and BI and another one } \\
\text { with core conditions MBE and BSB }\end{array}$ & 0.823 & 0.863 \\
\hline
\end{tabular}

